CONCISE REPORT

\title{
Diagnosis of calcium pyrophosphate dihydrate crystal deposition disease: ultrasonographic criteria proposed
}

\author{
B Frediani, G Filippou, P Falsetti, S Lorenzini, F Baldi, C Acciai, C Siagkri, D Marotto, M Galeazzi, \\ R Marcolongo
}

Ann Rheum Dis 2005;64:638-640. doi: 10.1136/ard.2004.024109

\begin{abstract}
Objective: To investigate by high frequency ultrasonography the appearance of calcium pyrophosphate dihydrate (CPPD) calcifications, in the most commonly affected sites in CPPD disease, and the relationship between ultrasonographic CPPD deposits and the presence of CPPD crystals in synovial fluid.

Methods: Three ultrasonographic patterns of CPPD calcification were identified and 11 patients enrolled. A control group comprised 13 patients with no evidence of CPPD deposits. Synovial fluid was aspirated from all patients and controls and examined for identification of crystals. All patients underwent a standard radiography examination at the same sites investigated by ultrasound.

Results: In all patients with ultrasonographically defined CPPD deposits, CPPD crystals were found in the synovial fluid. In two cases, standard radiographic examination did not show evidence of the calcific deposits that were identified by ultrasonography. CPPD crystals were not found in the synovial fluid of controls. In four control group patients, ultrasonography identified calcifications defined as deposits of another nature.

Conclusions: The ultrasonographic pattern used in this study for the diagnosis of CPPD disease demonstrated a very high correlation with the presence of CPPD crystals in synovial fluid. Ultrasonography demonstrated a sensitivity and specificity at least equal to that of radiography in identifying CPPD crystal calcifications.
\end{abstract}

$\mathrm{U}$ ntil now, the diagnosis of calcium pyrophosphate dihydrate (CPPD) crystal deposition disease has been based mainly on radiographic or microscopic detection of CPPD crystals.

Ryan and McCarty proposed several diagnostic criteria for the diagnosis of CPPD crystal deposition disease, ${ }^{1}$ based on the premise that CPPD crystals are the specific feature of the disease and including radiographic clues suggested by Resnick et $a l^{2}$ and Martel et al. ${ }^{3}$ According to these criteria, a case is definite if CPPD crystals are demonstrated in tissues or synovial fluid by definite means (for example, chemical analysis) or if crystals are demonstrated by compensated polarised light microscopy and typical calcifications are seen on radiographs. In this last case, if only one of these criteria is found, a probable diagnosis is made.

Ultrasound (US) is a very sensitive and specific technique for detecting calcifications of soft tissues, ${ }^{45}$ but only a few papers have described sonographic evidence of articular and periarticular changes caused by CPPD disease. ${ }^{6-9}$ In this paper we tried to define the US aspect of CPPD calcifications in order to propose ultrasonographic criteria for the differentiation of CPPD deposits and hyperechoic deposits of another nature. We then tried to verify the relationship between the ultrasonographically defined presence of CPPD calcifications in cartilage and periarticular tissues and the presence of CPPD crystals in the synovial fluid and compare the US findings with the radiographic findings.

\section{PATIENTS AND METHODS}

We enrolled in this study all patients with US evidence of CPPD calcifications in hyaline/fibrous cartilage and/or periarticular tissues, examined during four consecutive months (11 subjects). We used as control group 13 consecutive patients with no US evidence of CPPD calcification and who had mild osteoarthrosis. All patients had joint effusion, and at these sites we aspirated synovial fluid and performed a microscopic analysis for detection of CPPD crystals. The mean age of patients (two men, nine women) was 67.8 years (range 61-79) in the first group and of control group subjects (three men, 10 women) 65.2 years (range 59-74). In all cases, US examination was prescribed by the general physician for the presence of pain in one or more joints.

Based on the few existing publications, ${ }^{6-9}$ and our experience, we considered as CPPD calcifications all hyperechoic deposits that presented one of the following patterns:

- Thin hyperechoic bands, parallel to the surface of the hyaline cartilage (frequently observed in the knee) ${ }^{67}$

- A "punctate" pattern, composed of several thin hyperechoic spots, more common in fibrous cartilage and in tendons

- Homogeneous hyperechoic nodular or oval deposits localised in bursae and articular recesses (frequently mobile) (fig 1).

In all cases, calcifications had a sparkling appearance and created posterior shadowing only when they reached dimensions $>10 \mathrm{~mm}$. In contrast, calcifications that presented a hypoechoic appearance with posterior shadowing even at an early stage (2-3 $\mathrm{mm}$ in diameter) were considered as crystalline deposits of another nature, probably due to hydroxyapatite crystal deposition disease. ${ }^{10}$

All patients underwent US and then a radiological examination of the three ultrasonographically explorable sites most commonly affected by CPPD crystal deposition disease $\mathrm{e}^{11}$ : knee, wrist, and shoulder.

US examination was performed by an experienced sonographer, a specialist in rheumatology, who was unaware of the previous diagnosis. An Esaote Technos MP scanner with a 7.5-13 MHz dedicated linear transducer was used and the method has been described elsewhere. ${ }^{5}{ }^{12}{ }^{13}$ In most cases the standard scans proposed by the EULAR Working Group were sufficient for identifying the calcific deposits. Both axial and

Abbreviations: CPPD, calcium pyrophosphate dihydrate; MSU, monosodium urate; US, ultrasound 

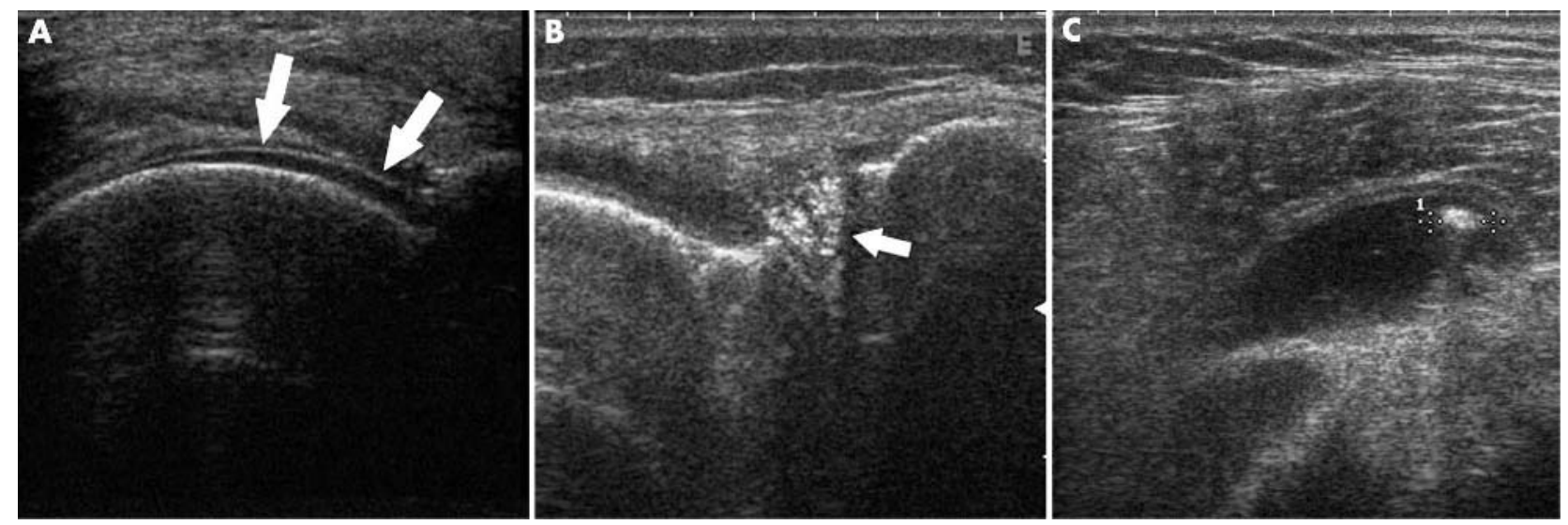

Figure 1 Ultrasonographic aspect of the three different patterns used in our study to define CPPD calcifications. (A) Thin hyperechoic band on the articular surface of the hyaline cartilage of the femur (arrows), (B) several sparkling spots in the lateral meniscus of the knee (arrow); (C) a mobile hyperechoic deposit not creating posterior shadowing (callipers) in the subacromial bursae of the shoulder.

longitudinal scans were carried out on cartilage and fibrocartilage (triangular fibrocartilage of the wrist, meniscus and hyaline cartilage of the femur) without lifting the probe along the entire portion of the cartilage and searching carefully for any type of deposit.

Radiographs were obtained with standard anteroposterior and lateral projections.

Synovial fluid analysis was performed on wet preparations, within an hour after aspiration, by an expert biologist who was unaware of the ultrasonographic and radiographic findings. Wet analysis was performed on slides obtained by placing a tiny drop of carefully shaken fluid onto a degreased slide that was then gently coverslipped. Each slide was observed under transmitted light microscopy with the condenser diaphragm placed as close as possible to enhance the refractivity of the crystals ("pseudophase" lighting), and by compensated polarised microscopy. At least 30 adjacent microscopic fields of each slide were carefully scanned. Crystals with a rod or rhomboid shape and weak birefringence with positive elongation were considered to be CPPD crystals. ${ }^{14}$

\section{RESULTS}

Ultrasonically defined CPPD calcifications were found in 11 patients. Nine of these had radiological evidence of calcifications at the same sites (table 1 ).

Crystals identified as CPPD were found in all subjects of the first group at microscopic analysis of the synovial fluid.
None of the control group patients had CPPD crystals in the synovial fluid; monosodium urate (MSU) crystals were found in one.

Hyperechoic deposits considered as calcifications "of another nature" were found in four control group patients. In all cases the calcifications were visible on standard radiographs. In three patients, joints with calcified deposits had an effusion; in one patient joint effusion was present in a distal joint; in no cases were crystals found.

\section{DISCUSSION}

US is a very sensitive and specific technique for detecting calcifications. In some cases calcifications detected by US may not be found in standard plain radiographs, ${ }^{11}$ because of the localisation of the deposit or the technique used. Magnetic resonance is not considered to be valuable in the detection of calcifications, probably owing to the lack of mobile protons in calcifications. ${ }^{15}$

In our study plain radiographs confirmed the presence of the US defined deposits "of another nature" in all cases. In two cases of CPPD deposits identified by US, standard radiographs did not confirm the diagnosis. In the first case, a nodular hyperechoic deposit that did not create an acoustic shadow ( $5 \mathrm{~mm}$, pattern II , fig 2) was found in the triangular fibrocartilage of the left wrist. The patient had a mild effusion of the radiocarpal joint of the left wrist $(0.7 \mathrm{ml}$ of synovial fluid was aspirated) and only a minor effusion on the right, so joint aspiration was not attempted. Only slight pain was

Table 1 Localisation of CPPD deposits in US/plain radiographs (+: present) and type of pattern found (pattern I, II, or III, see "Patients and methods")

\begin{tabular}{|c|c|c|c|c|c|c|c|c|c|}
\hline \multirow[b]{2}{*}{ Patient } & \multicolumn{3}{|c|}{ Wrist } & \multicolumn{3}{|c|}{ Shoulder } & \multicolumn{3}{|c|}{ Knee } \\
\hline & RX & US & Pattern & RX & US & Pattern & RX & US & Pattern \\
\hline 1 & & + & II & & & & & & \\
\hline 2 & & & & + & + & ॥ & + & + & I and || \\
\hline 3 & & & & & & & & + & II \\
\hline 4 & & & & & & & + & + & I and || \\
\hline 5 & + & + & ॥ & & & & + & + & II \\
\hline 6 & + & + & ॥ & & & & + & + & I and || \\
\hline 7 & + & + & ॥ & + & + & III & + & + & I and || \\
\hline 8 & & & & + & + & $\|$ & + & + & $\|$ \\
\hline 9 & + & + & $\|$ & & & & + & + & II \\
\hline 10 & & & & & & & + & + & II \\
\hline 11 & & & & & & & + & + & II \\
\hline
\end{tabular}



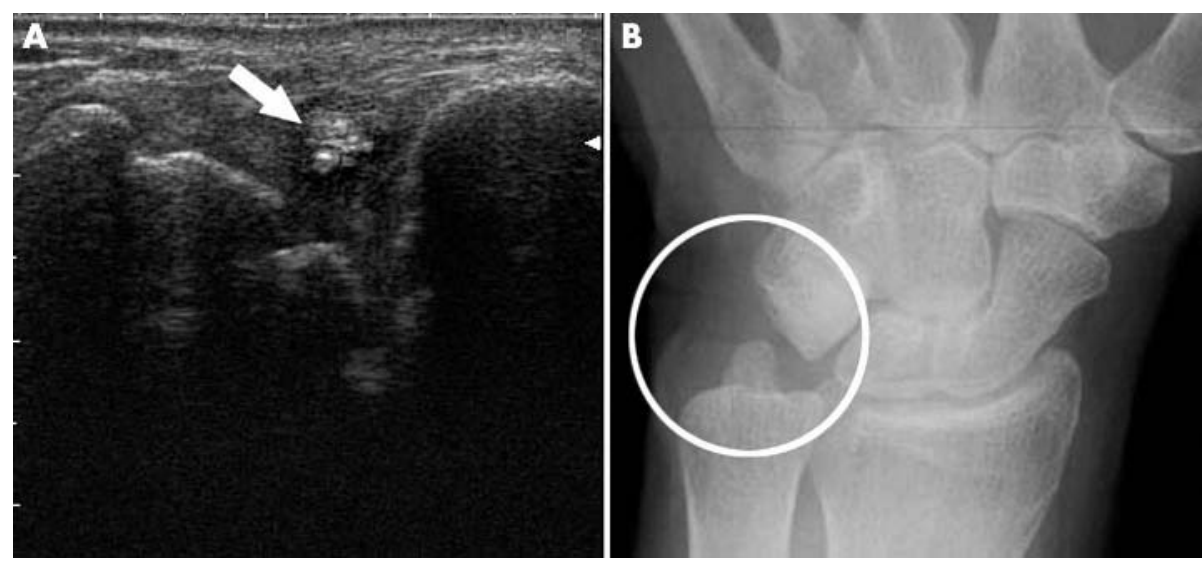

Figure 2 Several sparkling spots, shaping a nodular hyperechoic deposit compatible with CPPD calcification pattern II (arrow), not seen in plain radiographs (circle).

present. No evidence of calcification was found in the right wrist. In the second case, several sparkling spots were found in the lateral meniscus (pattern II), bilaterally, and a few were found in the posterior portion of the hyaline cartilage of the right knee. Mild effusion was present only on the right knee, but both joints were painful. In both cases, microscopic analysis disclosed several intracellular and no extracellular CPPD crystals. It is not clear why these deposits were not seen with radiology. Possibly, the lack of posterior shadowing had an important role (low density calcifications). These deposits might have been diagnosed by the use of a different intensity $x$ ray beam.

In all cases, in the first group, in which both US and radiographs were positive for the presence of calcifications, a large number of either intra- or extracellular CPPD crystals were found. In one case where MSU crystals were found, no specific US signs were found. The patient presented moderate articular swelling and important functional limitation due to pain. The US picture showed effusion and mild synovitis of the wrist joint.

Pattern II was the most common (found in at least one site in all patients). The third pattern was found in one patient with a large effusion in the subacromial bursae, where several mobile hyperechoic deposits were seen. A large number of CPPD crystals was found in the synovial fluid analysis, so we believe that the third pattern is seen when crystal aggregates are formed.

To our knowledge, only a few studies on the use of US in CPPD disease have been carried out, mostly in the knee joint. In these studies, average sensitivity and specificity in detecting calcifications were excellent. We believe that modern US equipment can provide useful indirect information on the structure of the deposit, based on the presence of posterior acoustic shadowing or the grade of echogenicity, and it permits an exact localisation of the deposit, helping to indicate its probable nature. The patterns used in this study were set empirically, mainly based on our experience, but proved to be reliable and permitted us to differentiate between probable CPPD and deposits of a different nature. It is too early to state that US will have an important role in early CPPD crystal deposition disease diagnosis. However, we believe that more studies, involving a larger number of patients, are required. The intrinsic characteristics of the technique (no $x$ rays, inexpensive, and repeatable) lead us to believe that it may be an important tool in early diagnosis and follow up of CPPD deposition disease.

\section{Authors' affiliations \\ B Frediani, G Filippou, P Falsetti, S Lorenzini, F Baldi, C Acciai, \\ C Siagkri, D Marotto, M Galeazzi, R Marcolongo, Department of \\ Clinical Medicine and Immunological Sciences, Section of \\ Rheumatology, University of Siena, Policlinico le Scotte, viale Bracci 53100 Siena, Italy}

Correspondence to: Dr G Filippou, g_filippou@virgilio.it

Accepted 12 August 2004

\section{REFERENCES}

1 Ryan LM, McCarty DJ. Calcium pyrophosphate crystal deposition disease, pseudogout and articular chondrocalcinosis. In: McCarty DJ, Koopman WJ, eds. Arthritis and allied conditions. 13th ed. Philadelphia: Lea and Febiger, 1997:2103-25.

2 Resnick D, Niwayama G, Goergen TG, Utsinger PD, Shapiro RF, Haselwood DH, et al. Clinical, radiographic and pathologic abnormalities in calcium pyrophosphate dehydrate deposition disease (CPPD): pseudogout. Diagn Radio 1977;122:1-15.

3 Martel W, McCarter DK, Solsky MA, Good AE, Hart WR, Braunstein EM, et al. Further observations on the arthropathy of calcium pyrophosphate crystal deposition disease. Radiology 1981;141:1-15

4 Bradley M, Bhamra MS, Robson MJ. Ultrasound guided aspiration of symptomatic supraspinatus calcific deposits. Br J Radiol 1995;68:716-19.

5 Backhaus M, Burmester G-R, Gerber T, Grassi W, Machold KP, Swen WA, et al. Guidelines for musculoskeletal ultrasound in rheumatology. Ann Rheum Dis 2001;60:641-9.

6 Coari G, lagnocco A, Zoppini A. Chondrocalcinosis: sonographic study of the knee. Clin Rheumatol 1995; 14:511-14.

7 Foldes K. Knee chondrocalcinosis. An ultrasonographic study of the hyaline cartilage. J Clin Imag 2002;26:194-6.

8 Kellner $\mathrm{H}$, Zoller W, Herzer P. Ultrasound findings in chondrocalcinosis. Z Rheumatol 1990:49:147-50

9 Monteforte P, Brignone A, Rovetta G. Tissue changes detectable by sonography before radiological evidence of elbow chondrocalcinosis. Int J Tissue React 2000;22:23-5.

10 Garcia GM, McCord G, Kumar R. Hydroxyapatite crystal deposition disease. Semin Musculoskelet Radiol 2003;7:187-93.

11 Genant HK. Roentgenographic aspects of calcium pyrophosphate dihydrate crystal deposition disease (pseudogout). Arthitis Rheum 1976; 19:307-28.

12 Brassier JL, Tardieu M. Ecografia dell'apparato locomotore, 1 st ed. Roma: Verduci Editore, 2001.

13 Monetti G. Ecografia muscolo-scheletrica ed imaging integrato, 1st ed. Napoli: Idelson-Gnocchi, 2000.

14 Schumacher H, Reginato A. Crystal identification. In:Atlas of synovial fluid analysis and crystal identification. 1 st ed. Philadelphia: Lea and Febiger, 1991:89-102.

15 Kamel M, Eid H, Mansour R. Ultrasound detection of heel enthesitis: a comparison with magnetic resonance imaging. J Rheumatol 2003;30:774-8. 